\title{
Avaliação das alterações de cor e brilho em compósitos resinosos de baixo custo nacionais
}

\author{
Mariana G. C. Soares*, Larissa J. H. Pinto, Débora A. N. L. Lima, Giselle M. Marchi, Rodrigo B. E. Lins, Renata \\ Pereira, Marcela A. Ferretti, Flávio H. B. Aguiar.
}

\begin{abstract}
Resumo
Este trabalho avaliou variações de cor e brilho de compósitos convencionais de baixo custo do mercado odontológico brasileiro, quando submetidos à escovação simulada. A partir de uma matriz de teflon, foram confeccionados 50 espécimes cilíndricos $(7 \mathrm{~mm} \times 2 \mathrm{~mm})$, que foram divididos em 5 grupos $(\mathrm{n}=10)$ : Filtek (Filtek-Z250) (3M Oral Care), Ultrafill- (Biodinâmica), FillMagic-(Coltene), Liss-(FGM), Applic-(Makira). Todas as amostras foram submetidas à análise de cor e brilho antes e após escovação. Os dados foram submetidos ao teste de normalidade (Shapiro-Wilk), seguidos por ANOVA 2-fatores e teste de Tukey $(\alpha=0.05)$. Os resultados mostraram que nenhum compósito apresentou mudança clinicamente significativa de cor após a escovacao $(\Delta \mathrm{E}<2.7)$. Filtek apresentou os maiores valores de $\Delta \mathrm{E}$, enquanto Fillmagic os menores. Ultrafill, LLis e Applic foram estatisticamente semelhantes à Filtek e FillMagic. Quanto ao brilho, antes da escovação os maiores valores foram obtidos por Filtek, seguido por FillMagic e Ultraffil. Applic não diferiu estatisticamente de Filtek, FillMagic e Llis. Llis não diferiu estatisticamente de FillMagic, Applic e Ultrafill. Após a escovação, Filtek apresentou os maiores valores de brilho, diferindo estatisticamente dos demais compósitos. Os valores de brilho diminuíram após escovação para todos os compósitos. Concluiu-se que a utilização de resinas compostas de baixo custo não apresenta prejuízos em relação as suas propriedades físicas, à curto prazo, quando comparada a uma resina composta comumente utilizada do mercado.
\end{abstract}

Palavras-chave: Resinas compostas, escovação dentária simulada, cor, brilho.

\section{Introdução}

A indústria odontológica lança frequentemente novos compósitos para suprir a demanda do mercado, sendo muitos com valores reduzidos a fim de atrair a classe odontológica para sua aquisição, e baratear custos de tratamentos e serviços. Essa demanda é observada em vários convênios odontológicos, os quais vem crescendo exponencialmente em território nacional. Para que ocorra a diminuição de custo do produto final, a qualidade do material resinoso se torna duvidosa. Desta forma, há necessidade de estudos aprofundados para avaliar a qualidade do material quanto suas propriedades físicas. O objetivo deste estudo foi avaliar alteração de cor e brilho superficiais de compósitos resinosos fotopolimerizáveis de baixo custo do mercado brasileiro, antes e após escovação mecânica.

\section{Resultados e Discussão}

Ao observar a Tabela 1, é possível notar que em todos os grupos, os valores de $\Delta \mathrm{E}$ foram inferiores a variação de cor clinicamente visível de 2.7.1 A não alteração de cor dos compósitos após a escovação simulada corrabora com a expectativa da manutenção estética de resinas compostas. É importante notar, no entanto, os resultados de brilho obtidos no presente estudo. De acordo com a Tabela 2, houve diminuição de brilho após a simulação de escovação mecânica para todos os compósitos. De forma geral, os valores de brilho entre todos os compósitos se mantiveram semelhantes após a escovação, com exceção de Filtek, que apresentou maior brilho quando comparado aos outros compósitos. A escovação simulada e os abrasivos presentes no dentifrício possivelmente desgastaram as matrizes orgânicas dos compósitos, resultando em uma superfície mais rugosa. $\mathrm{O}$ aumento da rugosidade pode levar à diminuição do brilho. ${ }^{2}$ É válido compreender que, salvo o dano estético em decorrência da diminuição do brilho, em curto prazo tal aumento de rugosidade pode não representar prejuízo às propriedades dos compósitos resinosos. A longo prazo, no entanto, o aumento da rugosidade pode levar a acúmulo bacteriano significativo e consequentemente alteração de cor também.

Tabela 1. Média (desvio padrão) de variações de Cor

Tabela 2. Média (desvio padrão) de Brilho (GU)

\begin{tabular}{lllll}
\hline $\begin{array}{c}\text { Compósit } \\
\quad\end{array}$ & \multicolumn{1}{c}{$\Delta \mathrm{L}$} & \multicolumn{1}{c}{$\Delta \mathrm{a}$} & \multicolumn{1}{c}{$\Delta \mathrm{b}$} & \multicolumn{1}{c}{$\Delta \mathrm{E}$} \\
\hline Ultrafiil & $-0.73(0.83) \mathrm{a}$ & $0.44(0.13) \mathrm{ab}$ & $-1.17(0.49) \mathrm{a}$ & $1.95(0.58) \mathrm{ab}$ \\
Llis & $-0.57(0.77) \mathrm{a}$ & $-0.03(0.62) \mathrm{c}$ & $-1.07(0.89) \mathrm{a}$ & $1.62(0.69) \mathrm{ab}$ \\
FillMagic & $-0.33(0.77) \mathrm{a}$ & $0.12(0.11) \mathrm{bc}$ & $-1.04(0.17) \mathrm{a}$ & $1.30(0.24) \mathrm{b}$ \\
Applic & $-0.87(0.73) \mathrm{a}$ & $0.58(0.18) \mathrm{a}$ & $-1.35(0.21) \mathrm{a}$ & $1.83(0.31) \mathrm{ab}$ \\
Filtek & $-0.49(0.52) \mathrm{a}$ & $\begin{array}{l}0.35(0.27) \\
\text { abc }\end{array}$ & $-1.25(2.59) \mathrm{a}$ & $2.48(1.50) \mathrm{a}$ \\
& & & &
\end{tabular}

\begin{tabular}{llc}
\hline \multicolumn{1}{c}{ Compósito } & \multicolumn{1}{c}{ Brilho inicial } & \multicolumn{1}{c}{ Brilho final } \\
\hline Ultrafill & $77.93(3.60) \mathrm{Ac}$ & $18.14(9.87) \mathrm{Bb}$ \\
Llis & $81.49(8.20) \mathrm{Abc}$ & $16.36(4.66) \mathrm{Bb}$ \\
Fill Magic & $83.42(5.98) \mathrm{Ab}$ & $18.74(4.09) \mathrm{Bb}$ \\
Applic & $85.86(2.77) \mathrm{Aab}$ & $18.13(5.78) \mathrm{Bb}$ \\
Filtek & $88.78(3.25) \mathrm{Aa}$ & $27.31(6.83) \mathrm{Ba}$
\end{tabular}

Letras

maiúsculas diferentes indicam diferença estatística entre colunas (tempo) e letras minúsculas diferentes indicam diferença estatística entre linhas (resinas compostas) $(p<0.05)$

\section{Conclusões}

A utilização de resinas compostas de baixo custo não apresenta prejuízos em relação a suas propriedades físicas, em curto prazo, quando comparada a uma resina composta comumente utilizada do mercado.

\section{Agradecimentos}

$\mathrm{PIBIC}-\mathrm{CNPq}$

${ }^{1}$ Reinhardt, JW.; Balbierz, MM.; Schultz, CM.; Simetich, B.; Beatty, MW. Oper Dent. 2019 Jan/Feb;44(1):65-75.

${ }^{2}$ Takahashi, R.; Jin, J.; Nikaido, T.; Tagami, J.; Hickel, R. e Kunzelmann, KH. Dent Mater J. 2013;32(1):75-82. 